\title{
DISTENSÕES E REPRESENTAÇÕES DO SERTÃO NO BRASIL: A REVISTA INTERIOR (1974-1989) ${ }^{1}$
}

- GUSTAVO SOARES IORIO ${ }^{2}$

Resumo : Na formaç̃ão histórica brasileira, assim como em outros casos, as ideias geográficas foram (e são) bastante expressivas enquanto argumento político. Num país de vasta área, há um imaginário sobre o território que permeia a constituição de formas sociais e legitima ações e intervenções sobre esse mesmo território. Neste artigo, examino uma ideia geográfica marcante na história desse país: 0 sertão. Mais especificamente, analiso o percurso, os meandros que essa ideia percorre na justa medida em que é dinamizada por agentes sociais concretos no âmbito da revista INTERIOR, publicada entre 1974 e 1989 pelo extinto Ministério do Interior. Tenho por objetivo compreender os significados desses contornos em um contexto social concreto.

Palavras chave: Imaginário do Sertão; História da Geografia no Brasil; Revista INTERIOR.

Introdução

ou construção simbólica (representações), a

A história da geografia tem geografia é parte subjacente às formações incursionado por caminhos reveladores não só sociais em geral. Este aspecto está sendo de suas ideias, mas, também, de suas práticas e bastante trabalhado por geógrafos e, inclusive, usos sociais. Enquanto manifestação fenomênica bem percebido por especialistas de outras áreas, 
revelando-se de significativa relevância para a compreensão do mundo social. As obras mais difundidas sobre o assunto não deixaram escapar as relações entre o saber geográfico e os projetos imperialistas, coloniais, de disputas hegemônicas e de legitimação de projetos políticos ${ }^{3}$.

$\mathrm{Na}$ formação histórica brasileira, a produção do território é também aspecto central, tanto no que tange à delimitação das fronteiras oficiais quanto aos processos que the dão conteúdo (MORAES, 2000). Este "imperativo territorial" (se é que é válida a expressão) não passou despercebido à intelectualidade nativa e manifestou-se nos mais importantes debates, em algumas das mais célebres interpretações do país e nos projetos de construção do Estado e da Nação. Essa "imaginação espacial" (MAIA, 2008; 2010) tampouco escapou à historiografia da geografia brasileira ${ }^{4}$. Desde algumas poucas décadas, esta historiografia tornou-se mais volumosa e avançou para mais temas e enfoques analíticos.

Aquilo que se pode chamar de imaginação espacial presente no pensamento e na formação histórica do Brasil é vasto e profundo, permitindo apreciações diversas, desde as mais gerais, como fizeram Andrade (1977), Pereira e Moraes (2005), por exemplo, às mais específicas, centradas particularmente em períodos, temas, processos ou instituições, como o fizeram Moraes (1991), Machado (2000; 2002) Souza Neto (2012), Sérgio Nunes Pereira $(2005 ; \mathrm{s} / \mathrm{d})$, entre tantos outros ${ }^{5}$.
Metodologicamente, essas análises nos remetem à apreciação da história da geografia brasileira em toda a sua pluralidade não linear de atores, instituições, ritos de consagração, conflitos e consensos. Trata-se de tomar a imaginação geográfica como uma prática social situada (DRIVER, 1992). Para o entendimento mais real dos significados das imaginações geográficas nas formações sociais, é desejável que essas ideias sejam analisadas em seus próprios contextos de interlocução, considerando-se os sujeitos sociais concretos que as produzem e as propagam, sem prescrever nenhuma determinação. Esse é o conteúdo da abordagem contextual, da qual nos fala Berdoulay (1981), e é, também, o sentido metodológico que nos orienta aqui.

Nesse artigo, analiso a trajetória da ideia de sertão no transcurso da revista INTERIOR à luz das frações e dinâmicas internas à própria revista. Nas páginas seguintes, procuro demonstrar como, em suas páginas, as diferentes maneiras de conceber o sertão estão relacionadas aos sujeitos e aos processos que a fazem. Interessa-me menos o conteúdo conceitual em si ${ }^{6}$ e mais a dinâmica resultante da dinamização por parte dos diferentes grupos que protagonizam a revista. As setenta edições de INTERIOR foram tomadas como base dos dados, além de uma entrevista com Valéria Velasco, editora-chefe da revista por praticamente todas as edições. 
Breves notas sobre o conceito de sertão no pensamento social brasileiro

Sertão é um vocábulo antigo na língua portuguesa. Ao que consta, precede até a colonização portuguesa na América. Presente nos textos cartográficos desde as primeiras representações, foi alçado à condição de chave interpretativa do país na virada do século XIX para o XX (AMADO, 1995; LIPPI, 1998; LIMA, 1999), através, principalmente, de Euclides da Cunha (2007).

Trata-se de um momento de intensos debates em torno da construção da nacionalidade e do Estado Nacional Brasileiro, no qual surgiram algumas das interpretações do Brasil mais consagradas. Questões como raça, meio e civilização foram equacionadas por diversos intelectuais na busca das respostas necessárias para a afirmação da recente República (MACHADO, 2002.). Nesse contexto, Euclides da Cunha enfrenta a questão da nacionalidade projetando sua atenção para os sertões (de Canudos à Amazônia). Nesse sertão, ele encontra o elemento mais original da nacionalidade, o sujeito brasileiro por excelência. Ao mesmo tempo, ali mesmo estaria a parcela não civilizada do país (MAIA, 2008). Nesses traços, Euclides da Cunha lança a ambiguidade que irá caracterizar todo o pensamento social brasileiro que recorre ao sertão para interpretar o Brasil: a autenticidade por um lado e a "incivilidade" por outro.
É importante ressaltar que o debate não se limita ao mundo dos "intelectuais", ou daqueles dispostos a pensar o país pelas vias do cientificismo da época. Há um amplo alcance da ideia de sertão que povoa distintos segmentos sociais. Moraes (2002-2003) fala de um imaginário do sertão, trazendo à tona $\mathrm{o}$ conteúdo político e a força simbólica que o termo tem

A revista INTERIOR foi também portadora de uma ideia de sertão, que se expressa em uma trajetória a partir de conteúdos próprios de seus agentes e do contexto de interlocução em que estava inserida. Na revista, está presente vasta gama de temas que, genericamente, estão articulados em torno da ideia de sertão (ou interior ${ }^{7}$ ) Fundamentalmente, a revista projeta sua atenção maior na abordagem desta parcela do país como maneira de compreendê-lo. Falar do sertão, do interior: eis o elemento constitutivo e conjuntivo de INTERIOR.

\section{A revista INTERIOR}

A revista INTERIOR surgiu em 1974, no primeiro ano de governo do general Geisel na forma de uma publicação oficial subordinada ao Ministério do Interior (MINTER), criado em 1967, quando o país já estava sob a tutela dos militares. Basicamente, a revista aborda temas relacionados ao escopo do ministério. A primeira edição leva a data de dezembro de 1974, e a última, número 70, sai em dezembro 
de 1989 (ao fim do governo de José Sarney, primeiro presidente civil depois dos militares), quando o próprio MINTER é dissolvido. Seus índices de tiragem começam por 20.000 exemplares e, após aumentos progressivos, chegam a 55.000 em 1979 (edição ${ }^{\circ}{ }^{2}$ 28), média mantida na maior parte de sua existência.

A revista vem a público exatamente no momento em que a legitimidade do pacto de poder dos governos militares começa a se deteriorar. A crise econômica tomava proporções maiores e colocava em risco a legitimidade do regime. Fazia-se necessário enfrentá-la efetivamente (através, por exemplo, de um ambicioso plano, o II Plano Nacional de Desenvolvimento - PND) e simbolicamente, o que reverberou um amplo investimento na imagem pública do regime através de iniciativas como a criação da Assessoria de Imprensa e Relações Públicas da Presidência (QUEIROZ, 1977) e a própria revista ${ }^{8}$.

\section{Os significados de uma revista}

Como é sabido, no momento em que a revista INTERIOR emerge efetivamente ao público, em dezembro de 1974, o Brasil vivia uma crise econômica que colocava em cheque a legitimidade do regime militar ancorada no ideário desenvolvimentista. Diante dessa situação, investimentos de ordem simbólica foram necessários para a manutenção do pacto de poder estabelecido. INTERIOR é a concretização de um desses investimentos. Para compreendê-la como uma trajetória discursiva, é necessário antes situá-la nesse contexto mais amplo, visualizar sua inserção no meio político e social. A questão que emerge daí é: por que o MINTER para abrigar uma publicação como essa?

Três elementos são decisivos para essa resposta: i) a função desempenhada por esse ministério; ii) a infra-estrutura de comunicação que o MINTER dispunha; iii) a presença de um indivíduo em particular: Orlando de Almeida e Albuquerque. Comecemos pelo primeiro: o MINTER foi um órgão abrangente em termos de competências - por exemplo: a ocupação territorial, assistência ao índio, saneamento básico, política nacional de habitação (BRASIL, 1967; 1970). Era também um ministério cuja figura sempre procurou estar estritamente vinculada ao desenvolvimento em $\mathrm{si}_{\text {; }}$ conforme dizia um de seus ministros, era o próprio "ministério do desenvolvimento" ${ }^{9}$. O MINTER seria, nessas condições, capaz de apresentar diversas ações sobre todo território nacional com a tônica do desenvolvimento.

Além dessas condições, sobressai o fato destacado por Jeová Franklin de Queiroz ${ }^{10}$ (1977), segundo o qual:

O Ministério do Interior (MINTER) se situa como o primeiro organismo, em seu nível e dimensão, na área do Poder Executivo, a desenvolver esforços efetivos para a reestruturação de suas atividades de comunicação 


\author{
social, sob a forma de \\ sistema, segundo uma base \\ mínima de fundamentação \\ técnica e científica. \\ (QUEIROZ, op.cit.p.3)
}

Ele mesmo diz ter participado da elaboração desse modelo como assessor através de um convênio estabelecido entre o MINTER e o Instituto Interamericano de Ciências Agrícolas (IICA) da Organização dos Estados Americanos (OEA), o que indica que já havia no MINTER uma preocupação efetiva com a comunicação social.

Além da natureza do ministério e seu já desenvolvido sistema de comunicação social, a pessoa de Orlando de Almeida e Albuquerque é também um elemento chave para se compreender o surgimento de uma revista como INTERIOR no âmbito do MINTER. Na ocasião do surgimento da revista, ele era o Chefe de Gabinete do Ministro Maurício Rangel, posição de destaque no órgão. Foi Diretor-Responsável da revista da primeira à vigésima sétima edição, num total de quatro anos, durante os quais assinou o editorial da edição inaugural e quase todos os outros editoriais neste intervalo de tempo. Sua participação como articulista também é efetiva. Foi sob sua diretoria também que a revista apresentou um crescimento vultoso no número de páginas e de tiragem.

O importante papel de Orlando Albuquerque é evidenciado por Valéria Velasco e Pontes ${ }^{11}$, editora chefe da revista nas setenta edições. Ela lhe atribui o papel de propositor:
O chefe do gabinete do ministro Rangel Reis [Orlando de Almeida e Albuquerque] propôs a criação da revista, ele era uma pessoa que tinha uma visão de comunicação muito boa, e ele queria mostrar esse trabalho de integração que estava sendo feito pelo ministério, aí decidiu mostrar por meio de uma revista. Ele resolveu criar a revista INTERIOR e resolveu me chamar para editar a revista.

Enfim, diante do contexto que demandava investimento em recursos de legitimação governamental, uma revista no formato que foi dado à INTERIOR foi de grande valia, e o MINTER era um órgão apto a conduzir semelhante empreitada em função de: i) sua própria natureza; ii) as condições infraestruturais favoráveis; iii) a presença de uma pessoa de alto gabarito no ministério com predisposição para fazê-la. Eis, pois, do ponto de vista da conjuntura externa à revista, os elementos que, articulados, a fazem ganhar vida. Passemos, agora, à sua apreciação do ponto de vista interno. 
Unidade e diferença entre os sujeitos, unidade e diferença entre as ideias

A revista INTERIOR é um conjunto de representações sobre o país e os processos em curso. Através de suas páginas, há certas categorizações, classificações, valorações e conceituações; em seus discursos, nomeia-se e atribui-se uma ordem específica. Os métodos, as formas do pensar que elaboram essa ordem, essas classificações são produtos de processos sociais conflituosos e dinâmicos. É o que Bourdieu (2007) chama de o poder de di-visão, o poder de instituir a forma de ver e, também, de dividir e unir o que se vê. A consagração de uma di-visão é, também, a efetivação do poder simbólico. Em torno dela, os agentes se articulam ou se rivalizam no campo das disputas simbólicas. Unidades e frações surgem.

Numa primeira aproximação, INTERIOR parece estar sincronizada com a representação do país segundo o MINTER. Entretanto, uma apreensão mais profunda sobre a revista revela que essa sincronia não é de toda verdadeira. Há aí um complexo conjunto de interelações que configuram unidades e frações. Uma análise mais aproximada revelou dois grupos distintos, mas não necessariamente opostos, que dão vida à revista. Um deles se forma em torno de Valéria Velasco; já o outro se dá como portavozes do discurso oficial. O pronunciamento de Valéria Velasco é bastante revelador:

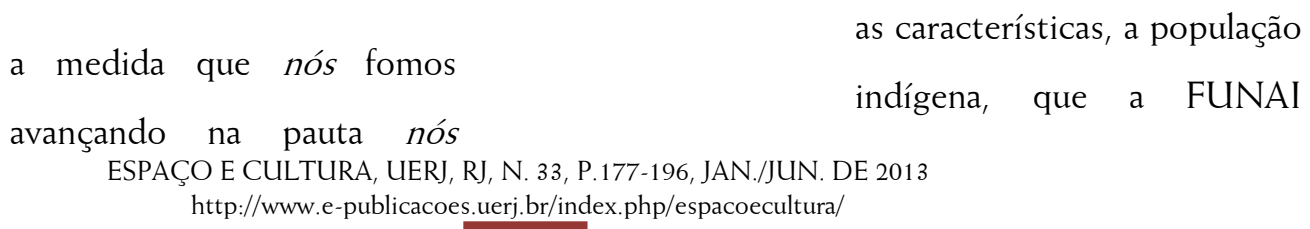
as características, a população indígena, que a FUNAI

fomos propondo uma
abertura pra assuntos que
estavam também, tinham
ligação de uma forma ou
outra com o projeto de
desenvolvimento e que
poderiam ajudar a tornar a
revista mais leve. Nós
começamos a mostrar por
exemplo a arte brasileira, o
artesanato das diversas
regiões, que tudo isso fazia
parte desse contexto da
proposta

desenvolvimento, porque que vai desenvolver aquela região, porque que esse projeto é o mais adequado. Então você pegava o projeto " $\mathrm{x}$ " $\mathrm{e} a$ gente mostrava no que isso ia interferir na vida da população dali e quem era essa população. Então a partir do momento que a gente estava mostrando quem era essa população a gente também mostrava o que ela fazia, ...então a gente começou a mostrar a parte de arte, literatura, ...então a gente começou a mostrar a literatura de cordel, o artesanato das várias regiões, 
[Fundação Nacional do

índio] também fazia parte do MINTER. Então a gente criou uma proposta de pauta, é..., mais 'humana' digamos assim, uma pauta cultural e voltada pro desenvolvimento humano ali, pras características da população daquela região, a proposta era integrar e mostrar essa integração, e mostrar quem era essa população brasileira, então com isso a gente, eu acho que a gente fez um trabalho muito importante porque nós mostramos um Brasil que era muito ainda desconhecido do resto da população, a gente estava chamando a atenção para aquele Brasil (grifo nosso)

Ao fazer referência a um "nós", ela particulariza um grupo. Ela revela ainda que esse "nós" se mobilizou para direcionar pautas, incluir um interesse próprio, distinto do interesse dos "outros". A passagem a seguir, extraída do editorial da edição número nove, de 1976, assinada também por Valéria Velasco, reforça essa ideia:

ESTA edição da revista INTERIOR traz a segunda de uma série de reportagens (a primeira, enfocando Caruaru, em Pernambuco, integrou o número de dezembro de 1975) que, abordando as cidades de todas as regiões, procurarão apresentar ao leitor algo de representativo da vida brasileira, através de uma pequena mostra das atividades nas quais estão empenhadas as comunidades que povoam nosso vasto interior (INTERIOR, n. 9. Março/Abril de 1976. p. 3. grifo nosso)

Essa "série de reportagens" que Valéria Velasco indica é, na verdade, a concretização da ação que descrita na passagem anterior. A anunciação da série, atribuindo a ela um caráter diferenciado, é o fator mais interessante. O que se anuncia aqui é a inserção de suas pautas, ou a pauta do grupo que se forma em torno dela, o "nós", que, doravante, será tratado como corpo editorial. Há um formato mais típico desse grupo, que o distingue dos "outros" (nós e outros, obviamente, do ponto de vista de Valéria Velasco), doravante ministerial ${ }^{12}$, que também estão associados no fazer da revista, cujas matérias são mais estilizadas, com textos mais rebuscados: partia-se de uma perspectiva diferenciada, destacando aspectos do cotidiano. Basicamente, o corpo-editorial tratava da cultura popular, trazia para as páginas da revista o folclore das cidades, dos lugares, das pessoas e do Meio Ambiente, como na seguinte passagem 
da matéria assinada por Jeová Queiroz sobre a Mata Atlântica:

No rastro das moto-serras e do fogo, depois da ilusão de lucro fácil com a fugaz fertilidade deixada pela mata assassinada, o verde é substituído pelos tons ressequidos do solo empobrecido, raso e marcado pela erosão. Paisagem monótona só modificada duas ou três vezes por ano por inundações que se repetem sempre cada vez em escala maior. (INTERIOR, n.56. Maio/Junho de 1984. p. 30)

Suas estratégias de inserção também são identificáveis. No começo da proclamada série de reportagens, as matérias eram facilmente identificadas pelos seus temas e seus formatos. Entretanto, de maneira não muito contextualizada, "encaixadas" pela habilidade do articulista, apareciam no texto menções a algum órgão ou entidade do MINTER. O trecho a seguir trata da cidade de Vila Boa de Goiás:

As festividades populares são eminentemente religiosas: procissão do fogaréu, à noite, com archotes, durante a Semana Santa; festa do Divino Espírito Santo, no primeiro domingo de julho; Festa de N.S. do Rosário, em outubro, tradição advinda do ciclo da mineração e calcada em costumes dos escravos.

Iniciativas novas: construção de um conjunto de casas populares, pelo $\mathrm{BNH}_{i}$ assentamento de meios-fios e construção de galerias de águas pluviais; uma praça no bairro São Francisco; pavimentação de ruas na periferia da cidade. (INTERIOR, $\mathrm{n}, \quad 9$. Março/Abril de 1976. p. 40. grifo nosso)

A matéria trata das riquezas culturais do município, explora o folclore e a sua riqueza histórica, e, como que de "supetão", faz referência ao Banco Nacional de Habitação $(\mathrm{BNH}) . \mathrm{O}$ autor (excepcionalmente não identificado) consegue habilmente inserir a informação com certa continuidade textual. Aos leitores, não passou despercebido o caráter especial dessas matérias, conforme se vê nesta passagem extraída da sessão "cartas", da própria revista:

[...] Mas é certo que não posso deixar de aplaudir a iniciativa de inserção, ao lado de textos mais técnicos, de temas que envolvam as cidades deste país que se sobressaem por alguma coisa: beleza, economia, folclore ou 
seus atrativos culturais. Da outra vez eu já havia me deleitado com a reportagem sobre Caruaru, mas achei que agora era indispensável lhes enviar esta carta a fim de estimulá-los a preservar nesta linha (INTERIOR, n. 14. Novembro/Dezembro de 1976. p. 50)

É fundamental destacar que não há elementos seguros que levem a considerar uma composição orgânica de fato desse grupo. Fundamental também é deixar claro que a distinção proposta entre os dois grupos não é, em hipótese alguma, uma contradição declarada, uma oposição tenaz. Não se trata de uma organização social aberta, com participação livre e oposições francas; trata-se se um órgão de governo, uma revista inserida na estrutura burocrática de um ministério em pleno regime militar. Há uma subordinação institucional irrevogável.

Este grupo estava mobilizado de maneira mais ou menos explícita. $\mathrm{Na}$ escolha dos articulistas pela editora chefe, está o fator aglutinador do corpo-editorial (mais ou menos identificado). Percebe-se que há um esforço efetivo, por parte de alguns articulistas e da editora chefa, em criar um espaço próprio, onde se expresse outra representação do Brasil. Efetivamente, o que mais caracteriza esse grupo é a representação de interior que ali está contemplada. Suas matérias, além do estilo e todas as outras marcas já apresentadas, partem de um ponto de vista conceitual próprio, de um sistema de ordenação, classificação, valoração, enfim, de di-visão do mundo, ou, mais precisamente, daquilo que está apresentado como sertão

Sertão, para eles, é o lugar 13 da cultura simples, mas mágica e profunda, forjada no sofrimento, na escassez de recursos, pobre em desenvolvimento, mas rico em profundeza humana, lócus privilegiado da cultura nacional. Valéria Velasco fala em um interior onde, possivelmente, o Brasil é mais representativo:

$\mathrm{Na}$ realidade, conhecer a pujança das grandes metrópoles, a atividade febril dos prósperos centros industriais e a concentração dos esforços que movimentam e transformam as capitais dos Estados não é suficiente para compreender e explicar o que é o Brasil: ele vive e pulsa também - e em certos aspectos mostrando características até mais representativas - nas ruas e praças das cidades interioranas, onde também se está construindo a grandeza do Brasil-potência. (INTERIOR, n. 9, Março/Abril de 1976. p. 3. grifo nosso.) 
Esse grupo se mobilizou para fazer da revista INTERIOR uma expressão do "Brasil dos brasileiros". Adotaram como tema as pessoas, os lugares, o folclore; mostraram a riqueza cultural autêntica, em contraposição à cultura de massas, pasteurizada: riqueza encontrada onde a cultura de massas não estava, onde a tradição estava arraigada.

Em contraposição, a grossa parte das pautas da revista levava outra tônica, que era protagonizada pelo grupo ministerial, representante da articulação da revista com a cúpula do MINTER. Orlando de Almeida Albuquerque era, simultaneamente, chefe de gabinete do ministro e o primeiro diretor da revista, entre 1974 e 1978. Sucedeu ele por apenas uma edição Luiz Ribeiro de Mendonça; em seguida, assumiu o cargo Nelson Braga O. Ferreira (entre 1979 e 1980), que era também coordenador de assuntos parlamentares do MINTER, subordinado ao Gabinete do ministro. Foi sucedido por Waldemir de Aragão Paiva (1980 a 1985), também Coordenador de Comunicação Social do MINTER. Em 1985, encerra-se o período militar e a direção da revista foi assumida pelo novo Coordenador de Comunicação Social, José Martins Arantes, que permaneceu até 1986; em 1987, foi sucedido por Milton Gontijo, que exerceu o cargo por somente uma edição e foi sucedido por Paulo César da Silva Gonçalves, que assumia também a Coordenadoria de Comunicação Social e permaneceu diretor até a extinção da revista.

Por todo o momento, a revista INTERIOR foi dirigida por membros da cúpula ministerial, na maioria das vezes o Coordenador de Comunicação Social do MINTER. As pessoas acima mencionadas, cada qual em seu devido tempo, lideraram o grupo denominado como ministerial, representavam a elite decisória do MINTER e eram a principal ponte entre governo e revista. Eles "rivalizavam" com o corpo editorial em condições desproporcionais de força, já que as decisões definitivas sempre lhes couberam.

Em aspectos gerais, o grupo ministerial, organicamente vinculado à elite dirigente do MINTER e, por consequência, ao projeto desenvolvimentista do governo, fez predominar uma representação do sertão como expressão do subdesenvolvimento, algo a ser transformado, dinamizado, modernizado. Um interior cuja civilização não se faz presente e onde as marcas do progresso não se efetivaram. Segue passagem de uma matéria de Orlando Albuquerque sobre o exército brasileiro que evidencia bem este sentido:

Também longe das vistas da quase totalidade $\mathrm{da}$ população, já quase se faz em rincões distantes, perdidos na imensidão da Amazônia, do Centro-Oeste e em espaços ainda fracamente povoados, é a ação das unidades de fronteira e colonização, num quase anônimo porém hercúleo trabalho naquelas extensas áreas onde só o uniforme verde-oliva marca a 
presença do homem e da civilização brasileira.

(INTERIOR, n. 9,

Março/Abril de 1976. p. 4. grifo nosso.)

As palavras destacadas expressam o suposto caráter incivilizado daquilo a que ele se refere como "rincões distantes". A fraca densidade populacional anuncia a natureza impávida em detrimento da civilização. Este grupo é o condutor da concepção mais clara de interior enquanto oposição ao mundo desenvolvido, ou "moderno". Eles são os proclamadores de um interior trabalhado politicamente pelo MINTER, o "ministério do desenvolvimento".

As divergências não são absolutas. Em primeiro lugar, elas estão em um nível sutil entre o declarado e o não declarado. Há, também, o fato de congregarem indivíduos em seus exercícios profissionais, o que implica em respeito a hierarquias e funções e, claro, preocupação com o emprego. Do ponto de vista das ideias, as divergências se expressam tão somente em torno de uma questão em comum: o sertão. Falar sobre o país do ponto de vista de seu sertão dá à revista uma unidade interna. Os dois grupos, em geral, versam basicamente sobre um "país profundo", expresso nos seus domínios mais "distantes", no interior, sertão ou fundos territoriais

Esse elemento em comum, conforme já foi dito, é um tema recorrente no pensamento social brasileiro. Conforme já dito, Euclides da
Cunha (op. cit.) consagra um tratamento ambíguo que representa o sertão enquanto atrasado, mas, também, como o pilar da nacionalidade. Essa ambiguidade se repete na revista INTERIOR, na qual o sertão aparece como subdesenvolvido e, igualmente, autêntico e original. A diferença é que, agora, os dois termos da ambiguidade são vivificados por grupos "concorrentes", não estão encarnados em uma só personalidade. A dinâmica que alimenta a trajetória ambígua do conceito de sertão, protagonizada por dois grupos distintos, é o que nos interessa na seção seguinte.

\section{O percurso de um conceito e seus meandros}

Em seus atos de concorrência e cooperação, os dois grupos, ministerial e corpo editorial, dão vida e dinamizam a revista INTERIOR. As ações desses sujeitos alimentam um processo contínuo de transformação. As variações (ou as frações) fazem-se perceptíveis no movimento em que estão inseridas. Uma forma social, quando apreendida enquanto um processo (e não como uma unidade estática), revela os agentes e as forças em curso (BARTH, 1993). INTERIOR, nesse sentido, se mostra como um processo, um movimento protagonizado por seus agentes e forças já identificados. Para caracterizar esse processo, recorro ao instrumento da periodização, longe de pretender com isso dispor períodos 
estanques e lineares. Ao contrário, os períodos, se enfocados pelas ações de força que o caracterizam, apresentam, mesmo que de maneira simplificada, com mais clareza a complexidade adjacente a todo processo social.

I. Concepção: Corresponde às edições de número um a cinco. Essas edições estão marcadas pelo caráter de divulgação de informações oficiais. As matérias são, na maioria das vezes, apresentações da natureza dos programas, setores e políticas do MINTER. Contêm explanações sobre as tarefas do Banco do Nordeste do Brasil (BNB), Companhia de desenvolvimento do Vale do São Francisco (CODEVASF), Superintendência de Desenvolvimento do Nordeste e da Amazônia (SUDENE e SUDAM), a Fundação Nacional do Índio (FUNAI) e o Projeto Rondon.

Não há traços que remetam à ação do corpo editorial. A revista está completamente hegemonizada pelo grupo ministerial. $\mathrm{Na}$ primeira edição, não se acusa nenhum editor chefe; já na segunda, José Julio Pontes é apresentado nesta função. A própria Valéria Velasco só aparece como editora-chefe na terceira edição. De uma forma geral, as matérias são mais próximas do formato jornalístico padrão.

II. Formatação: Período compreendido entre as edições seis e quatorze. É nesta fase que a revista se estabiliza, adquire seu formato que vai prevalecer por muito tempo. Atinge a tiragem de 45.000 cinquenta páginas em média. A ação dos dois grupos já é mais sensível. A edição seis traz uma matéria sobre os índios Karuap, cujo foco está projetado à cultura, com uma linguagem estilizada, cheia de fotos. Na edição seguinte, há uma matéria sobre Caruaru-PE, cuja tônica é o folclore e a cultura popular. Neste intervalo, aparecem ainda matérias sobre a cidade de Goiás-GO, Santarém-PA e Gramado-RS. São as evidências do corpo editorial se organizando e disputando espaço na revista.

Ainda assim, o discurso mais oficial é hegemônico. A oitava edição, por exemplo, é exclusiva sobre o Banco Nacional de Habitação $(\mathrm{BNH})$, elaborada com contribuição do setor de divulgação do banco. A décima é uma edição especial que aborda cada setor, órgão, entidade e território federal vinculados ao MINTER. Há ainda, nesse intervalo, uma sequência de reportagens sobre as Forças Armadas, todas assinadas por Orlando de Almeida e Albuquerque. Esse diretor é extremamente relevante. Parece que é em torno dele que os dois grupos se articulam, como se ambos tivessem seu respaldado. Por mais que assuma a condição protagonista do discurso oficial, parece consentir também com o grupo do corpo editorial, concedendo-lhe certa guarida.

A relação entre os dois grupos parece ser bem harmoniosa neste período. $\mathrm{O}$ grupo do corpo editorial parece aceitar bem sua condição menor a conquistar poucos espaços. Já o grupo ministerial, representado por Orlando Albuquerque, não parece incomodado, ao contrário, mostrando-se satisfeito com as inovações que a revista ganha. 
III. Era "Próalcool": Período compreendido entre as edições quinze e vinte e oito. Apesar de certa continuidade com o período anterior, há um fator novo na relação de convivência entre os dois grupos. As edições neste intervalo foram majoritariamente governistas. O grupo ministerial centralizou muito mais a revista, com todas as edições publicando artigos de autoridades no ministério, como o próprio ministro, e a transcrição de um discurso do então presidente Geisel. Os projetos governamentais tomaram conta das páginas da revista, notoriamente o Próalcool e a questão energética. $\mathrm{O}$ grupo do corpo editorial teve pouco espaço para se manifestar. Mesmo assim, demonstrando a efetividade desse grupo, é possível perceber a sua presença em edições como as vinte e dois e vinte e três, nas quais temas bem oficiais são tratados por um formato mais literário, ou mais "leve", com abordagem diferenciada e tratamento menos oficioso, como pode se observar nessa matéria sobre a Superintendência de Desenvolvimento da Borracha (SUDHEVEA):

Para onde vai tanta borracha?

Difícil, tarefa para muita imaginação, é descobrir onde não entra a borracha.

Imaginemos o Maracanã numa tarde de domingo, decisão de campeonato, 150 mil pessoas de olhos pregados em 22 homens que correm de um lado para o outro. Que fazem eles no campo retangular, coberto de grama, com quase $10 \mathrm{mil}$ metros quadrados? Simplesmente correm atrás de um artefato de borracha revestido de couro (INTERIOR, n.22. Janeiro/Fevereiro de 1978. p.4)

É a mudança de estratégia diante de um contexto desfavorável o que se observa.

IV. Simbiose: Período compreendido entre as edições vinte e oito e trinta e dois. Inicia-se sob a Presidência de Figueiredo e Mario Andreazza como ministro do Interior. Entre a última edição do período anterior e a primeira deste, há um intervalo de um ano, justificado no editorial da edição vinte e oito pelos problemas gerados na sucessão de governo. Este curto intervalo se deve ao caráter particular que essas edições têm. Com a troca dos altos cargos do MINTER, o grupo ministerial toma outra forma, menos articulado no que diz respeito à revista. Orlando Albuquerque deixa a revista e o ministério. Em seu lugar, assumiu, primeiramente, Luiz Ribeiro de Mendonça, somente na edição vinte e oito, e, depois, Nelson Braga O. Ferreira, da vinte e nove em diante.

Nessas quatro edições, há somente uma manifestação pessoal do diretor responsável pela revista (o editorial da edição vinte e oito). Todos os outros editoriais foram assinados por Valéria Velasco, editora chefe. Antes, Orlando 
Albuquerque era nome frequente como editorialista e/ou articulista. O corpo editorial ganhou espaço, mas a hegemonia não se alterou efetivamente. Matérias típicas desse grupo, por exemplo, foram pouco presentes. O que houve foi uma continuidade entre os dois grupos. $\mathrm{O}$ ministerial, menos articulado, permitiu maior espaço para o corpo editorial que o ocupou sem confrontar a forma mais oficial.

Credita-se a isso uma estrutura mais "leve" (conforme expressão de Valéria Velasco na entrevista), um espaço mais aberto, como ocorrido na edição trinta e dois, que traz um debate mais franco sobre a Amazônia, com depoimento de Aziz Ab'Saber. Diversas matérias ganham assinaturas de articulistas como Herval Cruz e Jeová Queiroz, bem próximos a Valéria Velasco, em matérias às vezes relacionadas a temas tradicionais do grupo ministerial. Em poucas palavras, esse período marcou uma gerência da revista pelo corpo editorial, porém de maneira respeitosa ao formato estabelecido pelo grupo ministerial.

V. Maturidade e complexificação: É o intervalo mais longo, compreendendo das edições trinta e três à cinquenta e cinco. Foi a fase mais estável (mesmo com a mudança de direção na edição trinta e cinco) e, também, mais dinâmica da revista. Concomitantemente, a assimilação e a contradição entre os grupos se intensificaram. O corpo editorial foi mais marcante que na fase anterior; suas matérias típicas se propagaram ${ }^{14}$. Mas o fator mais significativo é a estabilização de duas sessões mais ou menos regulares: "Memória Nacional" e "Cultura Popular", que institucionalizam o tema cultural na pauta habitual da revista. Por sua vez, o grupo ministerial também se fez mais presente pelas pautas, em que preponderaram as relativas aos programas e projetos do MINTER, além de matérias assinadas pelas autoridades governamentais.

Se os dois grupos delimitam as fronteiras que os separam, eles também dão continuidade ao processo descrito no período anterior, de entrelaçamento mútuo. Matérias como a de Jeová Queiroz sobre Rondônia (ed. trinta e sete), ou de Eduardo Brito sobre as exportações da Zona Franca de Manaus (ed. quarenta e dois), ou, ainda, de Carlos Ribeiro apresentando o artesanato do Vale do Jequitinhonha-MG por uma perspectiva desenvolvimentista (ed. quarenta e seis) apresentam um conteúdo mais oficial em um estilo mais literário.

VI. Era "Informe Especial": Esse período, compreendido em um pequeno intervalo entre junho e dezembro de 1983 (edições cinquenta e um, cinquenta e dois e cinquenta e três), é, na verdade, mais um hiato entre seus antecessor e sucessor. $\mathrm{O}$ intervalo de três edições marca a prevalência absoluta do grupo ministerial, em que aparece apenas uma matéria expressiva do corpo editorial, assinada por Severino Francisco, sobre o repente 
nordestino (ed. cinquenta e dois). No mais, predominam pronunciamentos de autoridades do MINTER e matérias que, de forma geral, trataram diretamente dos órgãos do ministério. Chama atenção a repetição monótona de matérias enquadradas em uma sessão intitulada de "Informe Especial". O formato que apareceu pela primeira vez na edição trinta e dois se repete por todas as edições sem regularidade, mas com relativa constância. nesse pequeno intervalo, porém, o "Informe

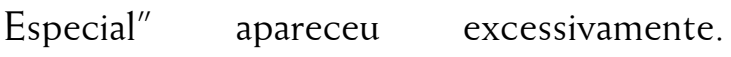
Basicamente, são textos rápidos, informativos, destinados a notificar algum acontecimento do ministério. A diagramação é chamativa, assemelhando-se muito a notas publicitárias.

As matérias assinadas escassearam. Quando apareciam, reproduziam a mesma linha, como a matéria de Jeová Queiroz sobre o guaraná na Amazônia (ed. cinquenta e dois) e a de Fernando Pinto sobre o Mato Grosso e Rondônia (ed. cinquenta e três). Na edição cinquenta e três, a última desse período, consta um total de seis "Informes Especiais". Mas, nessa mesma edição, como matéria de abertura, há uma reportagem sobre Augusto Rodrigues, artista popular, assinada por Thaís Mendonça. Esta modalidade de reportagem, de conteúdo cultural, se cristalizou e foi característica do período que sucede a este.
VII. Maturidade e Complexificação II: Período compreendido entre as edições cinquenta e quatro e sessenta. De uma maneira geral, assume as mesmas características que o quinto período, como se estivessem em uma continuidade interrompida. Porém, uma mudança há de ser considerada, que se deu em relação à "simbiose" anterior.

Neste período, o grupo corpo editorial demarcou espaço mais contundentemente. A seção "Cultura Popular" se cristaliza na abertura da revista em todas as edições deste intervalo; os temas de cultura e folclore popular e as linguagens sofisticadas ganharam espaço significativo. Mesmo assim, o grupo ministerial teve mais espaço (como sempre até então), e o demarcou bem com pautas características e a linguagem mais "fria". Aquela interpenetração anterior é dissolvida, as fronteiras estão melhor demarcadas e os grupos mais ou menos bem delimitados (tendo em vista que esta definição nunca esteve absolutamente estabelecida).

VIII. Quase corpo editorial: Este período (das edições sessenta e um-sessenta e dois à sessenta e seis) compreende uma fase muito particular da revista. Seu início é marcado pelo fim do regime militar. Apesar de poucas edições, estão aí compreendidos dois anos, de 1985 a 1987. Pela primeira vez, o corpo editorial assumiu espaço maior do que o seu "rival". Foi uma "avalanche" de matérias, desde o editorial até a metade da 
revista, para depois darem lugar às matérias mais tradicionalmente ministeriais. Pela primeira vez, há, na revista, um artigo assinado por Valéria Velasco.

Tal fato está atrelado ao período de transição governamental, em função do qual o MINTER não teria ainda se organizado suficientemente. Já o editorial da edição sessenta e três leva a assinatura de um novo diretor responsável, José Mario Arantes. Sua presença parece ter reequilibrado a interferência ministerial, freando a ascensão do corpo editorial. As edições sessenta e quatro e sessenta e cinco retomaram uma constância na composição da revista, o que não significou a supressão do corpo-editorial, que, mesmo assim, teve mais espaço que nos períodos anteriores. A ampliação significativa do corpo editorial trouxe consigo críticas ferrenhas ao regime anterior, como se verifica na matéria assinada por Jeová Queiroz (ed. sessenta e umsessenta e dois), uma das mais contundentes nesse sentido.

Por mais que o regime militar tenha se diluído oficialmente, a continuidade do grupo ministerial ainda é identificável pelo formato, os temas e as abordagens das matérias, que apresentam uma continuidade irreparável. Há uma mudança das pessoas e uma continuidade de ideias.

IX. O fechar das cortinas: Esse período é o derradeiro da revista, compreendendo as edições sessenta e oito e sessenta e nove. Os números sessenta e sete e setenta não foram encontrados nas bibliotecas consultadas ${ }^{15}$, o que por si só já é um fator a ser considerado (evidencia, provavelmente, uma desestruturação da revista em geral, que antecede a sua extinção). Poder-se-ia dizer que a totalidade absoluta das matérias publicadas carregava um tom estritamente "oficial", não fosse a matéria de José Mario Rodrigues sobre "Coxinho", uma figura maranhense. Fato é que, guardada essa exceção, a revista nestas duas edições foi mais "oficial" do que em qualquer outra passagem de sua história. Foram relacionadas matérias não só da pauta do MINTER como do governo federal. A mudança brusca se percebe também na sessão "cartas", que publicou manifestação quase que exclusiva de políticos, como senadores e deputados, acusando o recebimento de seus respectivos exemplares.

Por certo, os agrupamentos não caracterizam com precisão todos os elementos neles contidos. Entretanto, coerente com a finalidade objetivada, esta periodização é ilustrativa das forças que se mobilizam e dão forma e conteúdo à revista INTERIOR. Tratase de um instrumento criado por um órgão de governo, por um elemento da estrutura estatal brasileira; nele existe uma hierarquia clara e bem definida. São nas frações dessa estrutura rígida, porém, que as disputas acontecem, mesmo que submetidas a uma "harmonia" posta pela 
hierarquia institucional. Dessas disputas, emergem e se colocam as diferentes representações do sertão que os sujeitos portam. É a minúcia desse movimento que essa periodização se pretende esclarecedora.

\section{Considerações finais}

A análise da revista INTERIOR revela um processo complexo, que ocorre em diferentes escalas de maneira entrelaçada. A condição de publicação oficial não a coloca mecanicamente como simples emissora de um discurso elaborado em um nível maior, como se o seu enunciado não pertencesse a si mesmo. Esse nível maior (o governo do regime militar) indiscutivelmente está representado como um dos agentes desse discurso. Por outro lado, a análise mais próxima da revista traz à tona uma dinâmica sutil mais efetiva. Para além de simples emissária, a revista apresenta um conteúdo mais ambíguo materializado pela ação de seus sujeitos mais elementares, aqueles que a fazem em seu dia-a-dia. Esses sujeitos são, sim, agentes efetivos, portadores de projetos e intencionalidades próprios, que são colocados nas frestas e contradições de uma unidade que é sempre fracionada.

Em termos de elaboração de ideias e representações sobre uma realidade (o poder de di-visão do mundo), isso é muito significativo. As intenções que alimentaram a criação da revista, conforme foi visto, passam pela propagação de um discurso oficial sobre o Brasil e os processos de "desenvolvimento" que transformavam o sertão. Nessa perspectiva, esse "lugar" foi abordado como um atraso a ser incorporado ao mundo das relações capitalistas de produção. Objetivamente, entretanto, essa intenção inicial, apesar de não ter sido anulada em momento nenhum, teve que concorrer com uma outra representação do mesmo lugar. Sertão, nessa outra perspectiva, era a autenticidade nacional que se esvaía diante daquilo que os primeiros chamavam de desenvolvimento. Isso quer dizer que, em meados da década de 1970, se vê revivida com muita força uma ambiguidade no pensamento social brasileiro que surge na virada do século XIX para o XX.

Em termos de história das ideias, a revista INTERIOR não está no mesmo patamar que um autor clássico como Euclides da Cunha. Entretanto, a revista pode ser rico objeto de análise quando o interesse analítico reside na compreensão das formas sociais concretas que as ideias tomam no conjunto das relações sociais; como elas se propagam; como são recriadas, reinventadas; como elas estão dispostas no universo da negociação e do convencimento. 
${ }^{1}$ Este artigo representa parte das pesquisas de mestrado, apresentadas ao PPGG/UFRJ, e de doutorado, na mesma instituição. Agradeço a contribuição de minha orientadora, Ana Daou, e aos professores Antônio Carlos de Souza Lima, Lia Osório Machado e Sérgio Nunes.

2 Doutorando pelo Programa de Pós Graduação em Geografia da Universidade Federal do Rio de Janeiro (PPGG/UFRJ). Bolsista do Conselho Nacional de Desenvolvimento Científico e Tecnológico (CNPq). Email: gustavosoaresiorio@yahoo.com.br.

${ }^{2}$ Muitos poderiam ser elencados como obras de referência, dentre eles, no Brasil, destaco: GOMES, 2000; CAPEL, 1981; CLAVAL, 1981.

${ }^{3}$ Os trabalhos mais largamente utilizados são: PEREIRA, 1956; MONTEIRO, 1980, PETRONE, 1979; ANDRADE, 1977; BERNARDES, 1982.

${ }^{4}$ Alguns bons exemplos de trabalhos nessa perspectiva podem sem encontrados na revista de história do pensamento geográfico Terra Brasilis [http://redebrasilis.net/revista-terra-brasilis/] ou nos anais dos encontros nacionais de história do pensamento geográfico.

${ }^{5}$ Para uma abordagem mais focada no conteúdo conceitual em si na revista INTERIOR, ver Iorio, 2012.

${ }^{6}$ Para o sentido que o vocábulo sertão assume nesse artigo, considero-o como equivalente a interior. Para uma definição mais precisa, ver Iorio $(2010 ; 2012)$.

7 Para uma apresentação mais ampla da revista e uma pormenorização maior do contexto e dos significados de seu surgimento, ver lorio (op. cit.).

${ }^{8} \mathrm{O}$ Ministério do Interior costuma ser visto apenas em seus aspectos conjunturais, no atendimento a necessidades imediatas, mas ele é muito mais do que isso; é um Ministério para tratar dos grandes problemas estruturais da Nação', afirma o ministro Ronaldo Costa Couto. É exatamente por isso que ele prefere ver sua pasta como um Ministério do Desenvolvimento. (INTERIOR, n. 61/62. Março/Junho de 1985. p. 14)

${ }^{9}$ Jeová Queiroz foi um dos mais destacados articulistas da revista INTERIOR, assinou diversas matérias e reportagens, e um dos mais elogiados pelos leitores nas cartas publicadas na seção "cartas", que encerrava as edições a partir do número 14 .
${ }^{10}$ Valéria Velasco e Pontes foi por mim entrevistada em 04/04/2009 em seu escritório em Brasília. Aproveito para agradecer a atenção, solicitude e delicadeza com que me recebeu.

${ }^{11}$ Esses desígnios são meramente ilustrativos, a fim de facilitar a identificação dos grupos.

${ }^{12}$ É importante registrar que a ausência de uma referência telúrica definida é um dos elementos caracterizadores do imaginário do sertão, trabalhado por Moraes (2002-2003). Nesse sentido, sertão é um lugar multiforme, a depender do contexto discurso.

${ }^{13}$ É digna de nota a matéria sobre a ilha de Alcântara-MA assinada por Jeová Queiroz na edição 40, provavelmente o mais belo texto das setenta edições de INTERIOR.

${ }^{14}$ São as seguintes: Biblioteca Central da Universidade Federal de Viçosa (UFV), Biblioteca do Centro de Ciências Exatas e da Natureza da Universidade Federal do Rio de Janeiro (CCMN/UFRJ) e as Bibliotecas da Faculdade de Filosofia e Ciências Humanas e da Faculdade de Arquitetura e Urbanismo da Universidade de São Paulo (FFLCH-FAU/USP). As referências dessas edições foram acusadas, dentre todas as consultadas, somente no sistema de busca via internet da Biblioteca do Senado Federal, em Brasília.

\section{REFERÊNCIAS BIBLIOGRÁFICAS}

AMADO, J. Região, Sertão, Nação. Estudos Históricos, vol 8, n $15,1995$.

ANDRADE, M.C. de. O pensamento geográfico e a realidade brasileira. Boletim Paulista de Geografia, São Paulo, nº54, pp. 5-16, 1977.

BARTH, F. The complexity of civilization. In: BARTH, F. Balinese Worlds. Chicago: The University of Chicago Press, 1993. pp. 337-354.

BERNARDES, N. A influência estrangeira no desenvolvimento da Geografia no Brasil. In: Revista Brasileira de Geografia. Rio de Janeiro, 44(3), pp.519-527, jul./set. 1982.

BERDOULAY, V. The contextual approach. In: STODDART, D.R. (ed.). Geography, ideology and social concern. Oxford: Blacwell, 1981. pp. 8-16.

BOURDIEU, P. O Poder Simbólico. $11^{\mathrm{a}} \mathrm{ed}$. Rio de Janeiro: Bertrand Brasil, 2007.

BRASIL. Decreto-lei $n^{\circ} 200$ de 25 de fevereiro de 1967. Disponível

em: 
$<$ http://www.lex.com.br/coletanea/default.aspx $>$. Acesso em 28/06/2007.

Decreto $n^{\circ} 66.882$ de 16 de julho de 1970.

Disponível em: $<$ http://www6.senado.gov.br/legislacao/ListaPublicacoes.a ction? $\mathrm{id}=197266>$. Acesso em 24/03/2009.

CAPEL, H. Filosofía y ciencia en la geografía contemporánea. Barcelona: Barcanova, 1981.

CLAVAL, P. Evolución de la geografía humana. $2^{\mathrm{a}}$ ed. Barcelona: Oikos-Tau, 1981.

da CUNHA, E.. Os Sertões. 9a Ed. Rio de Janeiro: Record, 2007

DRIVER, F. Geography's of empire: histories of geographical knowledge. Environment and planning $D$ : Society and space, 10 (1), pp. 23-40, 1992.

GOMES, P. C. da C. Geografia e Modernidade. $2^{\mathrm{a}}$ ed. Rio de Janeiro: Bertrand Brasil, 2000.

LIMA, N. T. Um sertão chamado Brasil: intelectuais e representação geográfica da identidade nacional. Rio de Janeiro: Revan: IUPERJ: UCAM, 1999.

IORIO, G. S. Síntese da vida nacional e representação do interior no Brasil: a revista INTERIOR (1974-1989). Dissertação (Mestrado em Geografia) - Programa de PósGraduação em Geografia, Universidade Federal do Rio de Janeiro, Rio de Janeiro, 2010.

Imagens e Imaginário do Sertão no Brasil sob Regime Militar: a revista INTERIOR (1974-1989). Scripta Nova, Barcelona, v. XVI, edição especial, 2012.

LIPPI, L. A conquista do espaço: sertão e fronteira no pensamento brasileiro. História, Ciências, Saúde, Manguinhos. Rio de Janeiro, vol. V (suplemento), julho 1998.

MACHADO, L. As idéias no lugar: o desenvolvimento do pensamento geográfico no Brasil no início do século XX. Terra Brasilis, Rio de Janeiro, Ano I, no 2, pp. 11-31, Jul/Dez 2000

O. Origens do pensamento geográfico no Brasil: meio tropical, espaços vazios e a idéia de ordem (18701930). In: CASTRO, I. E de; GOMES, P. C. da C.; CORRÊA, R. L. Geografia: Conceitos e temas. $4^{\mathrm{a}} \mathrm{ed}$. Rio de Janeiro: Bertrand Brasil, 2002.

MAIA, J. M. E. A terra como invenção: o espaço no pensamento social brasileiro. Rio de Janeiro: Zahar, 2008.
As ideias que fazem o Estado andar: imaginação espacial, pensamento brasileiro e território no Brasil Central. Dados - Revista de Ciências Sociais, Rio de Janeiro, vol.53, nº 3 , pp. 621-655, 2010.

MONTEIRO, C.A. de F. A Geografia no Brasil (19341977): avaliação e tendências. São Paulo: IGEO-USP, 1980. (série Teses e Monografias).

MORAES, A.C.R. de. Notas sobre identidade nacional e institucionalização da geografia no Brasil. Estudos Históricos, Rio de Janeiro, v.4, n.8, pp. 166-176, 1991

Bases da formação territorial do Brasil: o território colonial brasileiro no "longo" século XVI. São Paulo: HUCITEC, 2000.

Sertão: um outro geográfico. Terra Brasilis. Rio de Janeiro, n. 4-5, 2002-2003.

Território e História no Brasil. $2^{\mathrm{a}}$ ed. São Paulo: Annablume, 2005.

PEREIRA, S. N. Obsessões geográficas: viagens, conflitos e saberes no âmbito da Sociedade de Geografia do Rio de Janeiro. Revista da $S B H C$, Rio de Janeiro, v. 3, $\mathrm{n}^{\circ} 2$, pp. 112-124, jul./dez. de 2005.

Na boca do serão ou integrada ao ecúmeno? Militares, estatísticos, geógrafos e a localização da nova capital. Mimeo, s/d.

PEREIRA, J.V. da C. A Geografia no Brasil. In: AZEVEDO, F. As Ciências no Brasil. São Paulo: Melhoramentos, 1956. pp. 316-412.

PETRONE, P. Geografia Humana. In: FERRI, M. G.; MOTOYOMA, S. (coords.) História das Ciências no Brasil. São Paulo, Edusp, 1979. pp. 304-330.

QUEIROZ, J. F. de. Um estudo sobre a comunicação social no serviço público brasileiro. Dissertação de Mestrado. Universidade de Brasília. Brasília, 1977.

SOUZA NETO, M. F. de. Planos para o Império: os planos de viação do Segundo Reinado (1869-1889). São Paulo: Alameda, 2012.

\section{Fontes documentais}

INTERIOR. Brasília: Ministério do Interior. Anos I-XV, $\mathrm{n}^{\circ}$ 1- 69, dezembro de 1974 à setembro de 1989. Bimestral.

\section{THE DISTENSIONS AND THE REPRESENTATIONS OF THE INTERIOR IN BRAZIL: THE MAGAZINE INTERIOR (1974-1989)}

ESPAÇO E CULTURA, UERJ, RJ, N. 33, P.177-196, JAN./JUN. DE 2013

http://www.e-publicacoes.uerj.br/index.php/espacoecultura/ 
ABSTRACT: IN THE HISTORICAL FORMATION OF BRAZIL, AS IN THE OTHERS CASES, THE GEOGRAPHICAL IDEAS WERE (AND STILL ARE) VERY EXPRESSIVE AS A POLITICAL ARGUMENT. IN A COUNTRY OF VAST AREA, THERE IS AN IMAGINARY ABOUT THE TERRITORY THAT PERVADES THE CONSTITUTION OF SOCIAL FORMS AND LEGITIMIZES ACTIONS AND INTERVENTIONS ON THE SAME TERRITORY. IN THIS ARTICLE I EXAMINE A GEOGRAPHICAL IDEA REMARKABLE IN THE HISTORY OF THIS COUNTRY: THE BACKCOUNTRY. MORE SPECIFICALLY, I ANALYZE THE ROUTE, THE TWISTS AND TURNS THAT THIS IDEA RUNS AS IT IS FEATURED BY SOCIAL AGENTS WITHIN THE INTERIOR MAGAZINE, PUBLISHED BETWEEN 1974 AND 1989 BY THE EXTINCT MINISTRY OF INTERIOR. I HAVE AIMED TO UNDERSTAND THE MEANINGS OF THESE CONTOURS IN A CONCRETE SOCIAL CONTEXT.

Keywords: Backcountry Imaginary; History of Geography in Brazil; INTERIOR magazine.

LES DISTENSIONS ET LES REPRÉSENTATIONS DE L'INTÉRIEUR AU BRÉSIL: LA MAGAZINE INTERIOR (1974-1989)

RESUMÉ: DANS LA FORMATION HISTORIQUE DU BRÉSIL, COMME DANS D'AUTRES CAS, LES IDÉES GÉOGRAPHIQUES ÉTAIENT (ET SONT) TRÈS EXPRESSIVE COMMENT ARGUMENT POLITIQUE. DANS UN PAYS DE GRANDE SUPERFICIE, IL Y A UNE IMAGINAIRE SUR LE TERRITOIRE QUE IMPRÈGNE LA CONSTITUTION DES FORMES SOCIALES ET LÉGITIME DES ACTIONS ET DES INTERVENTIONS SUR LE MÊME TERRITOIRE. DANS CET ARTICLE, J'EXAMINE UNE IDÉE GÉOGRAPHIQUE REMARQUABLE DANS L'HISTOIRE DE CE PAYS: L'ARRIÈRE-PAYS. PLUS PRÉCISÉMENT, J'ANALYSE LA ROUTE, LES TOURS ET DÉOURS DE CETTE IDÉE PRÉCISÉMENT COMMENT El EST ALIMENTÉ PAR DES AGENTS SOCIAUX DANS LE INTERIOR MAGAZINE, PUBLIÉ ENTRE 1974 ET 1989 PAR L'ANCIEN MINISTÈRE DE L'INTÉRIEUR. J'Al CHERCHÉ À COMPRENDRE LA SIGNIFICATION DE CES CONTOURS DANS UN CONTEXTE SOCIAL CONCRET.

Mots-clés: Imaginaire de l'Arrière-pays; Histoire de la Géographie au Brésil; INTERIOR magazine. 